\title{
Basic information requirements for designing COVID-19 disease registration system
}

\section{Sorayya Rezayi and Marjan Ghazisaeedi}

Department of Health Information Management,

School of Allied Medical Sciences,

Tehran University of Medical Sciences,

Tehran, Iran

Email: s_rezayi@razi.tums.ac.ir

Email: ghazimar@tums.ac.ir

\section{Shahrzad Amirazodi}

Department of Management and Health Information Technology,

School of Management and Medical Information,

Isfahan University of Medical Sciences,

Isfahan, Iran

Email: amirazoodi@yahoo.com

\section{Soheila Saeedi*}

Department of Health Information Management,

School of Allied Medical Sciences,

Tehran University of Medical Sciences,

Tehran, Iran

and

Clinical Research Development Unit of Farshchian Heart Center,

Hamadan University of Medical Sciences,

Hamadan, Iran

Email: saeedi_s@razi.tums.ac.ir

Email: so.saeediii@gmail.com

*Corresponding author

\begin{abstract}
Collecting data related to COVID-19 disease can significantly impact the management of this pandemic. One of the tools that can be helpful in controlling this disease is developing registry. This study aimed to determine the technical and data requirements of the registry for COVID-19. Databases with keywords related to 'COVID-19' and 'registry' were searched. The existing registries in COVID-19 in Iran and other countries were examined. To finalise the data elements, focus group sessions were held with experts. Thirteen main data classes were identified: demographic information, critical dates, type of sample, patient condition, signs and symptoms, history of smoking and consuming narcotics, history of drugs consumption, imaging finding, differential diagnoses of a severe respiratory disease syndrome,
\end{abstract}


underlying conditions, complications of the disease, respiratory support and discharge outcomes. Determining data requirements is the first step in developing a registry that can create a standard infrastructure for consistent data collection.

Keywords: registry; data requirement; COVID-19; focus group; minimum dataset; MDS.

Reference to this paper should be made as follows: Rezayi, S., Ghazisaeedi, M., Amirazodi, S. and Saeedi, S. (2022) 'Basic information requirements for designing COVID-19 disease registration system', Int. J. Electronic Healthcare, Vol. 12, No. 1, pp.41-53.

Biographical notes: Sorayya Rezayi currently studies at the Department of Health Information Management in Medical Informatics discipline, Tehran University of Medical Sciences, Tehran, Iran. She is interested in the research area of wearable system design, telemedicine, and artificial neural network in medicine. She has a Master's in Medical Informatics from Tarbiat Modares University, Tehran, Iran.

Marjan Ghazisaeedi is a faculty member at the Department of Health Information Management, School of Allied Medical Sciences, Tehran University of Medical sciences, Tehran, Iran. She has experience in telemedicine, clinical dashboards, clinical decision support systems, health information systems and electronic health records.

Shahrzad Amirazodi has a Master's in Heath Information Technology (HIT) from Kashan University of Medical Sciences, Kashan, Iran. She is interested in medical informatics research and HIT topics.

Soheila Saeedi currently studies at the Department of Health Information Management in Medical Informatics discipline, Tehran University of Medical Sciences, Tehran, Iran. She is interested in medical informatics research topics. Soheila Saeedi has a Master's in Health Information Technology from Kashan University of Medical Sciences, Kashan, Iran.

\section{Introduction}

On 29 December 2019, hospital physicians in Wuhan, China, noticed unusual pneumonia cases (Mani et al., 2020). A new emerging virus is classified as an RNA virus that belongs to the coronaviruses' family, mostly have been led to respiratory tract infections (Yang et al., 2020). nCoV-2019 infection is a respiratory infection associated with a new, unknown coronavirus that has emerged as a human-animal transmissible virus (Tanne et al., 2020). The virus may have mutated or adapted to cause disease in humans. Thus, the outbreak of COVID-19 began in China, and all countries became involved in this global pandemic (Isaifan, 2020). On 11 March 2020, Severe Acute Respiratory Syndrome Coronavirus 2 (SARS-CoV-2), the virus causes coronavirus disease 2019 (COVID-19) was declared a universal pandemic by the World Health Organization (Cornejo-Pareja et al., 2020). The number of infected patients worldwide is rising dramatically every day and leads to many people's quarantine and the closure of industries (Chakraborty and Maity, 2020). Due to the novel and unknown nature of new coronavirus disease, the 
world faces particular challenges and difficulties in controlling and surveillance the disease (Uğur and Akbıyık, 2020). All the scientists and researchers in the world are trying to fight and face this new outbreak by collecting real-time information about infected patients. Given that the burden of COVID-19 disease is significant and considerable, the researchers decided to apply data infrastructure and information technology to enhance efficient research, timely treatment, and disease monitoring and control (Mohammadzadeh et al., 2020a). Systematic registration of diseases, or so-called registry, is an organised system for collecting clinical data to assess the consequences of a particular disease, condition, or exposure in a defined population and serve predetermined scientific, clinical, or political purposes (Akazawa et al., 2018). The collected data, data collection methods, the created reports, and their use vary according to the registry type. Registries may also differ by purpose, location, level of coverage, and type of organisation (Kazemi-Arpanahi et al., 2020). Clinical registries possess an immense standard potential for tracking the clinical outcomes, comparing the efficacy of numerous interventions, describing disease natural progression, evidence-oriented therapy, and post-marketing drug surveillance (Javanmard et al., 2020; Kodra et al., 2017). Furthermore, this system is an ideal tool for clinical study when improving health care quality is essential. In many diseases, registry systems are used for epidemiological studies, preliminary studies, risk modelling and other purposes (Sabbaghi et al., 2020).

Providing more appropriate and effective care, facilitating rapid and accurate diagnoses, faster and more extensive access to the patient's medical history, reducing the risk of adverse drug effects or unsatisfactory response to the treatment, and improving productivity and managerial effectiveness are among the possible benefits of using the registry system for COVID-19 infection (Dandachi et al., 2020). COVID-19 registration system is considered as a data source for standardising a comprehensive data set on the unknown dimensions of the disease (Javanmard et al., 2020); in other words, based on the data point recorded in it, the severity of the disease, prognostic factors, effectiveness and complications of treatment protocols, prediction of survival, prevalence and incidence of the disease in the country, clinical phenotype and the possibility of accurate monitoring can be determined (Kodra et al., 2017; Dandachi et al., 2020).

Although establishing and implementing such a system may seem expensive and complicated, it reduces the burden of disease and its consequences, like mortality, and is cost-effective in the future. The first step in designing a registry system is to determine the system's data requirements that have been addressed in this research.

\section{Material and methods}

This descriptive cross-sectional study was conducted in 2020. This study tried to examine the technical and clinical data requirements related to developing a registry for COVID19 outbreak. In order to determine the clinical and technical data requirements, a literature review was done to identify national and international systems and scientific literature related to COVID-19. This scientific review aimed to identify the administrative, clinical, and technical requirements of registries designed in this field. First, Scopus, Medline (through PubMed), Web of Science, IEEE, and Google Scholar databases were searched, and also Iranian databases, including IranMedex, Magiran, and SID, were examined for studies in Persian. For this purpose, we used a combination of keywords (('registries' [mesh] OR 'registry system' OR 'disease registry' OR 'clinical 
registry' OR 'clinical data registry' OR 'patient registry' OR 'population registry') AND ('2019 novel coronavirus disease' OR 'COVID19' OR 'COVID-19 pandemic' OR 'SARS-CoV-2 infection' OR 'COVID-19 virus disease' OR '2019 novel coronavirus infection' OR 'coronavirus disease 2019' OR '2019-nCoV disease' OR 'novel coronavirus 2019 disease')). In the next step, the systems and registries used in Iran and other countries to record the data of COVID-19 patients were investigated. The systems that used in Iran to record data related to COVID-19 patients were 'medical care monitoring centre' (MCMC) and 'syndromic surveillance system of infectious diseases' (ISSS). MCMC system has been created to organise medical services monitoring through effective and efficient communication, accelerating services, improving the quality of services, improving processes, and integrating management. This system has been developed in Iran by the Emergency Organization and has a purpose beyond recording the information of COVID-19 patients and is not specific to this disease. The primary purpose of ISSS system is the early detection and reporting of community-based epidemics. ISSS system, like MCMC, is not designed to manage COVID-19 disease. To review the technical requirements related to the development of registries, all sources reviewed these requirements were examined separately in the mentioned databases. Based on an investigation of scientific literature and existing registries in the field of COVID-19, the initial data elements were identified. To finalise the technical requirements, focus group sessions were held with six experts in health information technology, and medical informatics. Another focus group session was designed to determine the clinical and administrative data requirements with the physicians, nurses, health information management, and medical informatics experts (six experts).

\section{Results}

Based on conducted surveys from experts and investigating two national systems, MCMC and ISSS, data elements and requirements were determined for developing COVID-19 registry system. Finally, thirteen critical data elements were identified for designing the mentioned registry system that includes as follow:

1 demographic information

2 critical dates

3 type of sample

4 patient condition

5 signs and symptoms

6 history of smoking and consuming narcotics

7 history of drugs consumption

8 imaging finding

9 differential diagnoses of a severe respiratory disease syndrome

10 underlying conditions

11 complications of the disease 


\section{2 respiratory support}

13 discharge outcomes.

As can be seen in Table 1, thirteen main items have sub-items that are listed in detail. Notably, clinical registries are big databases comprising information about individuals affected by a specific condition; therefore, Figure 1 shows the specific features of the COVID-19 (specific requirements) disease registration system. In this Figure, the title of the disease registration program, the population under study, the registration's geographical scope, the main objectives of the registration, the definition of the disease, the method of diagnosis and the type of registration are given. In the following, Figure 2 presents the main functions of the disease registry system; the significant functions of COVID-19 registry are to provide multiple views of information for various people.

Table 1 Main information elements for designing coronavirus disease (COVID-19) registry system

\begin{tabular}{|c|c|c|c|}
\hline \multicolumn{4}{|c|}{1 Demographic information } \\
\hline First/last name & National ID & Gender & Father's Name \\
\hline Nationality & $\begin{array}{l}\text { Age (If it is less than } \\
\text { one year, mention it in } \\
\text { the month) }\end{array}$ & Province of residence & City of residence \\
\hline Phone number & Address & Birth date & - \\
\hline \multicolumn{4}{|c|}{$2 \quad$ Critical dates } \\
\hline Admission date & Admission time & Hospitalisation date & Isolation date \\
\hline $\begin{array}{l}\text { Sample submission } \\
\text { date }\end{array}$ & Sampling date & - & - \\
\hline \multicolumn{4}{|c|}{3 Type of samples (items selection) } \\
\hline Throat swab & Noise swab & $\begin{array}{l}\text { Cerebrospinal fluid } \\
\text { (CSF) }\end{array}$ & Necropsy \\
\hline Throat gargle & Tracheal tube suction & $\begin{array}{l}\text { Bronchoalveolar lavage } \\
\text { (BAL) }\end{array}$ & Sputum induction \\
\hline \multicolumn{4}{|c|}{$4 \quad$ Patient condition } \\
\hline $\begin{array}{l}\text { How to go to the } \\
\text { medical centre }\end{array}$ & COVID-19 test result & $\begin{array}{l}\text { Result of CT-scan of } \\
\text { lungs }\end{array}$ & $\begin{array}{l}\text { Previous history of } \\
\text { COVID-19 infection }\end{array}$ \\
\hline $\begin{array}{l}\text { History of contact } \\
\text { with a patient with } \\
\text { COVID-19 }\end{array}$ & $\begin{array}{l}\text { Travel history in the } \\
\text { last seven days }\end{array}$ & Bird contact history & Animal contact history \\
\hline $\begin{array}{l}\text { History of contact } \\
\text { with foreign } \\
\text { travellers }\end{array}$ & Number of breaths & SPO2 rate (percentage) & Temperature rate \\
\hline Intubation & - & - & - \\
\hline \multicolumn{4}{|c|}{$5 \quad$ Signs and symptoms (items selection) } \\
\hline \multicolumn{4}{|c|}{$5.1 \quad$ Influenza-like key symptoms } \\
\hline $\begin{array}{l}\text { Fever over } 38 \\
\text { degrees }\end{array}$ & Sore throat & Cough & - \\
\hline \multicolumn{4}{|c|}{5.2 Symptoms of the lower respiratory tract } \\
\hline Shortness of breath & Chest pain & External pharynx & Difficult breathing \\
\hline Bloody sputum & - & - & - \\
\hline
\end{tabular}


Table 1 Main information elements for designing coronavirus disease (COVID-19) registry system (continued)

\begin{tabular}{|c|c|c|c|}
\hline \multicolumn{4}{|c|}{5.3 Cardiovascular symptoms } \\
\hline Chest pain & Low blood pressure & - & - \\
\hline \multicolumn{4}{|c|}{$5.4 \quad$ Nerves systems symptoms } \\
\hline Vertigo & Drowsiness & Convulsion & Loss of consciousness \\
\hline \multicolumn{4}{|c|}{ Auxiliary symptoms } \\
\hline $\begin{array}{l}\text { Loss or reduction of } \\
\text { smell sense }\end{array}$ & $\begin{array}{l}\text { Loss or reduction of } \\
\text { taste sense }\end{array}$ & Muscular pain & eye redness \\
\hline Headache & Vomiting & Diarrhoea & Stomach ache \\
\hline Sneezing & Skin lesions & Joint pain & Anorexia \\
\hline $\begin{array}{l}\text { Redness of the } \\
\text { conjunctiva }\end{array}$ & Nasal congestion & Paralysis of the limbs & Abnormal hearing \\
\hline Bruising of the skin & - & - & - \\
\hline \multicolumn{4}{|c|}{$6 \quad$ History of smoking and consuming narcotics } \\
\hline History of smoking & $\begin{array}{l}\text { History of using } \\
\text { narcotics }\end{array}$ & - & - \\
\hline \multicolumn{4}{|c|}{7 History of drugs consumption } \\
\hline $\begin{array}{l}\text { Long-term use of } \\
\text { aspirin }\end{array}$ & $\begin{array}{l}\text { Long-term use of } \\
\text { immunosuppressive } \\
\text { drugs }\end{array}$ & chemotherapy & cortisone \\
\hline \multicolumn{4}{|c|}{8 Imaging finding } \\
\hline CRX & Bilateral infiltration & Ground-glass opacities & - \\
\hline Chest CT-scan & Bilateral infiltration & Ground-glass opacities & - \\
\hline \multicolumn{4}{|c|}{9 Differential diagnoses of severe respiratory disease syndrome (items selection) } \\
\hline $\begin{array}{l}\text { Seasonal flu } \\
\text { pneumonia }\end{array}$ & Diphtheria & Measles & $\begin{array}{l}\text { Severe acute } \\
\text { respiratory syndrome } \\
\text { (SARS) }\end{array}$ \\
\hline Legionella & Pneumonic plague & $\begin{array}{c}\text { Human } \\
\text { metapneumovirus } \\
\text { (HMPV) }\end{array}$ & Parainfluenza \\
\hline Chikungunya & $\begin{array}{l}\text { Atypical pneumonia/ } \\
\text { mycoplasma }\end{array}$ & Chlamydia & - \\
\hline \multicolumn{4}{|c|}{10 Underlying conditions } \\
\hline $\begin{array}{l}\text { Chronic liver } \\
\text { disease }\end{array}$ & Diabetes mellitus & Blood Disorder & HIV (AIDS) \\
\hline Pregnancy & High blood pressure & Asthma & $\begin{array}{l}\text { Chronic neurological } \\
\text { disorders }\end{array}$ \\
\hline $\begin{array}{l}\text { Acquired/ } \\
\text { congenital } \\
\text { immunodeficiency }\end{array}$ & $\begin{array}{l}\text { Cancer/chemotherapy } \\
\text { condition }\end{array}$ & $\begin{array}{c}\text { Chronic kidney disease } \\
\text { (CKD)/dialysis } \\
\text { condition }\end{array}$ & $\begin{array}{c}\text { Lack or removal of the } \\
\text { spleen }\end{array}$ \\
\hline Obesity & Malnutrition & - & - \\
\hline
\end{tabular}


Table 1 Main information elements for designing coronavirus disease (COVID-19) registry system (continued)

\begin{tabular}{|c|c|c|c|}
\hline \multicolumn{4}{|c|}{11 Complications of the disease } \\
\hline \multicolumn{4}{|c|}{11.1 Pulmonary complications } \\
\hline Bronchitis & $\begin{array}{l}\text { Primary pneumonia } \\
\text { (viral) }\end{array}$ & $\begin{array}{l}\text { Secondary pneumonia } \\
\text { (bacterial) }\end{array}$ & Pulmonary embolism \\
\hline Pulmonary edema & $\begin{array}{l}\text { Acute respiratory } \\
\text { distress syndrome } \\
\text { (ARDS) }\end{array}$ & - & - \\
\hline \multicolumn{4}{|c|}{ 11.2 Cardiac complications } \\
\hline Myocarditis & $\begin{array}{c}\text { Pericarditis } \\
\text { myocardial infarction } \\
(\mathrm{MI})\end{array}$ & Heart failure & - \\
\hline Endocarditis & - & - & - \\
\hline \multicolumn{4}{|c|}{ 11.3 The nervous and central system complications } \\
\hline Meningitis & Encephalitis & Meningoencephalitis & $\begin{array}{l}\text { Cerebral venous sinus } \\
\text { thrombosis (CVST) }\end{array}$ \\
\hline $\begin{array}{l}\text { Intracranial } \\
\text { bleeding }\end{array}$ & Resistant epilepsy & - & - \\
\hline \multicolumn{4}{|c|}{11.4 Renal/blood complications } \\
\hline $\begin{array}{l}\text { Pyelonephritis } \\
\text { (cystitis) }\end{array}$ & Acute tubular necrosis & Uremia & $\begin{array}{l}\text { Bleeding following } \\
\text { thrombocytopenia }\end{array}$ \\
\hline $\begin{array}{l}\text { Disseminated } \\
\text { intravascular } \\
\text { coagulation (DIC) }\end{array}$ & - & - & - \\
\hline \multicolumn{4}{|c|}{12 Respiratory support } \\
\hline Process start date & Process end date & - & - \\
\hline \multicolumn{4}{|c|}{13 discharge outcomes } \\
\hline \multicolumn{4}{|c|}{13.1 Discharged patient information } \\
\hline Date of discharge & $\begin{array}{l}\text { Condition of discarded } \\
\text { patients }\end{array}$ & - & - \\
\hline \multicolumn{4}{|c|}{ 13.2 Deceased patient information } \\
\hline $\begin{array}{l}\text { Death in the } \\
\text { hospital }\end{array}$ & $\begin{array}{c}\text { Death in outside of the } \\
\text { hospital }\end{array}$ & $\begin{array}{l}\text { Name of the unit where } \\
\text { the patient died }\end{array}$ & - \\
\hline $\begin{array}{l}\text { Intensive care unit } \\
\text { (ICU, CCU, NICU, } \\
\text { PICU) }\end{array}$ & Date of death & - & - \\
\hline
\end{tabular}


Figure 1 The specific features of the COVID-19 registration system (see online version for colours)

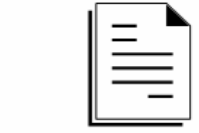

Registration program title (The title of the registration should be brief and include the main content of the registration and the area covered by it.)

- In this study system name is "COVID-19 registry system."
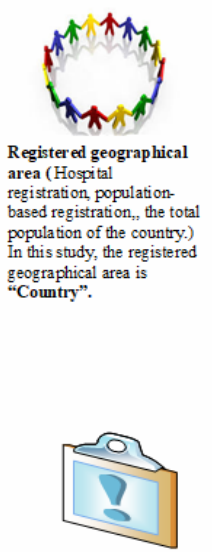

The main purposes of registration (Care objectives, research objectives.

In this study main purposes are rehted to care and research.

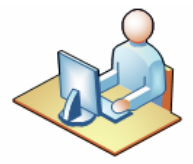

Healthcare Provider

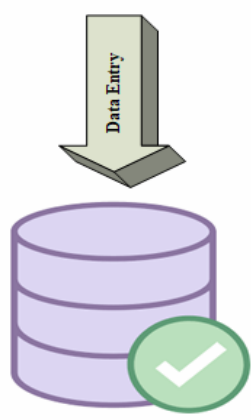

Definition of diseas - Determining the specific clinical and pathological science of a person with a specific diagnosis

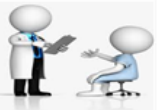

Patient diagnosis method ( how to follow patients)

In this study me thods are Laboratory tests, Imaging, Screening

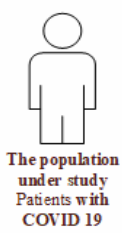

2. Patient Conditio

2-Patient Condition

3- Type of samples

3- Signs and symptoms

4- History of smoking and narcotics

5- History of drugs consumption

6- Underlying conditions

7-Complications of the disease

8- Final information

Figure 2 Essential functions of disease registry (see online version for colours)
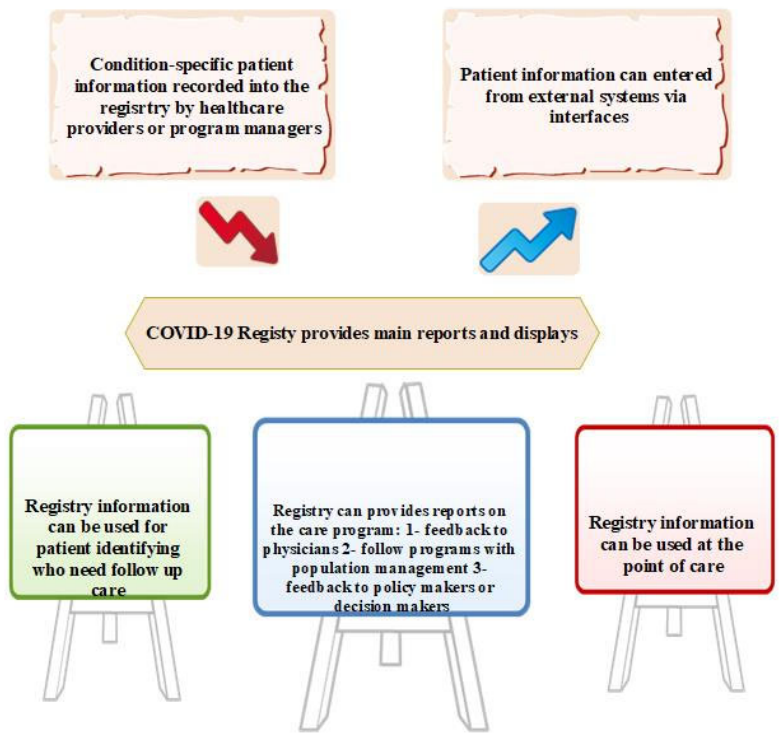

Types of registration

Clinical registration.

This registry system is clinical type. 
Based on a run survey of medical informaticians and health information managers, some of the COVID-19 registration system's technical requirements have been identified, which are listed in Table 2. In this table, the external interface requirements of designing a registry system were determined.

Table 2 Technical requirements of developing COVID-19 registry

\begin{tabular}{ll}
\hline External interface requirements & \multicolumn{1}{c}{ Specific technical aspects } \\
\hline User interfaces & - The system graphics are such that the user works with it \\
& with complete satisfaction and has high graphics. \\
Hardware interfaces & - Several users can use it simultaneously \\
- The system must be capable of spatial changes & - Management of the disease registration system \\
- Toftware interfaces & The system must be able to determine the level of users' \\
& - The system must be compatible with the plans of \\
& insurance organisations, hospital information systems. \\
& - The system must be compatible with the Internet \\
- The system can work with the network & - The system must be able to exchange information with \\
& HIS hospital information systems. \\
& - The standards of exchange, terminology, unit, and \\
& uniform coding should be used to record and exchange \\
& information. \\
- NoSQL: MongoDB, Redis, Casandra & Net framework, Vb.net, Microsoft Visual Studio, SQL \\
Software designing & Server
\end{tabular}

\section{Discussion}

This study aimed to determine the data requirements for the COVID-19 disease registry. After investigating the existing systems and expert surveys, thirteen main data classes were identified.

Thirteen main data classes for designing the mentioned registry system were as follows:

1 demographic information

2 critical dates

3 type of sample

4 patient condition

5 signs and symptoms

6 history of smoking and consuming narcotics

7 history of drugs consumption 
$8 \quad$ imaging finding

9 differential diagnoses of a severe respiratory disease syndrome

10 underlying conditions

11 complications of the disease

12 respiratory support

13 discharge outcomes.

Using registries in the healthcare field can lead to data collection related to diseases in a unified and standard way. By storing health data in the registry, the progress of diseases can be described, and also the quality of health care can be evaluated. The registries can be used to evaluate the cost-effectiveness of the treatments provided (Choinière et al., 2017). Determining the registry's minimum data set and critical requirements is a big step in designing and developing these systems. Designing a registry for epidemics, especially the COVID-19 epidemic, provide a reliable infrastructure for collecting COVID-19 data. With the help of registries in this area, the epidemiological investigation can be facilitated, and policymakers can better plan based on the registries' information and monitor the disease's progress (Kazemi-Arpanahi et al., 2020). Clinical data registry can provide valuable insights to health care providers, health care policymakers, and researchers regarding the characteristics of patients with COVID-19, the treatment patterns used, and the clinical outcomes of these patterns in hospitalised patients (Alger et al., 2020; Mohammadzadeh et al., 2020b).

The data elements identified for the registry in this study were classified into 13 main classes that can generally be divided into administrative and clinical data categories. A study conducted by Shanbehzadeh et al. (2020) determined the minimum data set for the surveillance system in COVID-19 disease. In this study, 11 main classes and 137 fields were determined; the highest number of data elements was related to demographic information with 27 fields and laboratory information with 21 fields. In the present study, 11 fields were related to demographic information, and more emphasis was on patients' clinical data (Shanbehzadeh et al., 2020).

Registry data has been used in the COVID-19 epidemic for various purposes, leading to valuable knowledge creation. In a study by Uribarri et al. (2020), international registry data were used to evaluate the effect of kidney disease on the mortality rate of COVID-19 disease, and it was concluded that these patients had more complications and mortality than other patients. In Spain, a registry has been used to improve knowledge in clinical, prognostic, diagnostic, and therapeutic aspects. This study has yielded valuable results and concluded that one in three patients with COVID-19 manifests respiratory distress, and one in five patients dies (Casas-Rojo et al., 2020). In Denmark, with the help of data recorded in the registry, they examined the mortality rate of patients with COVID-19. They concluded that timely lockdown significantly impacted the infection process, and the mortality rate did not increase (Mills et al., 2020). As mentioned, by collecting structured and unstructured data in the registers, valuable knowledge can be created and provided to policymakers to plan (Hasan et al., 2019).

With the advent of COVID-19 disease and the need to record data, many countries began to create national registries. In Iran, a registry devoted to COVID-19 disease has not been developed, but two systems, MCMC and ISSS, are used to record administrative and clinical data related to COVID-19. Determining data elements and requirements can 
be the first and most significant step in establishment of a data registry for COVID-19 disease. It can be used to determine survival estimation, the effectiveness and side effects of drugs used, disease prevalence in different parts of the country, and it can be used as a tool for researchers and policymakers with the purpose of planning (Irie et al., 2020; Kazemi-Arpanahi et al., 2019).

The strength of this study was the methods applied to determine the data elements. In this study, the scientific literature was first reviewed, and all the data elements required for COVID-19 patients were identified. In the next step, the existing systems and registries in COVID-19 disease were examined, which led to the identification of more data elements. Finally, based on a survey of experts, the necessary data elements needed to monitor patients were identified and confirmed.

\section{Conclusions}

This study represents data requirements and essential elements for developing a Coronavirus disease (COVID-19) registry system. Accessing this registry system led to that health care providers can call patients infected new emerged Coronavirus disease 2019 with specific needs, receive immediate feedback on their performance, deliver planned cares, and establish reminder systems. By applying this disease registry, the healthcare team can follow their patients individually and by population subset, allowing them to provide proactive care and treatment to individual patients or groups of similar patients. Therefore, remarkably the registry of COVID-19 has a significant role in improving medical knowledge, creating a platform for research, and increasing the quality of health services provided to patients. Meanwhile, this study's results can encourage researchers to use the registry system in the care of patients, forecasting prevalence or incidence rate and screening field; it can help the decision makers and policymakers make better decision regarding managing and preventing the COVID-19 in the countries.

\section{Funding}

In this paper, we did not have any financial sponsor.

\section{Availability of data and material}

All data generated or analysed during this study are included in this published article.

\section{Compliance with ethical standards}

Ethical approval: This article does not contain any studies with human participants performed by any of the authors. 


\section{References}

Akazawa, M., Mikami, A., Tamura, Y., Yanagi, N., Yamamura, S. and Ogata, H. (2018) 'Establishing a pharmacy-based patient registry system: a pilot study for evaluating pharmacist intervention for patients with long-term medication use', Pharmacy, March, Vol. 6, No. 1, p.12.

Alger, H.M., Williams IV, J.H., Walchok, J.G., Bolles, M., Fonarow, G.C. and Rutan, C. (2020) 'Role of data registries in the time of COVID-19', Circulation: Cardiovascular Quality and Outcomes, May, Vol. 13, No. 5, p.e006766.

Casas-Rojo, J.M., Antón-Santos, J.M., Millán-Núñez-Cortés, J., Lumbreras-Bermejo, C., Ramos-Rincón, J.M., Roy-Vallejo, E., Artero-Mora, A., Arnalich-Fernández, F., García-Bruñén, J.M., Vargas-Núñez, J.A., Freire-Castro, S.J., Manzano-Espinosa, L., Perales-Fraile, I., Crestelo-Viéitez, A., Puchades-Gimeno, F., Rodilla-Sala, E., Solís-Marquínez, M.N., Bonet-Tur, D., Fidalgo-Moreno, M.P., Fonseca-Aizpuru, E.M., Carrasco-Sánchez, F.J., Rabadán-Pejenaute, E., Rubio-Rivas, M., Torres-Peña, J.D. and Gómez-Huelgas, R. (2020) 'Clinical characteristics of patients hospitalized with COVID-19 in Spain: results from the SEMI-COVID-19 Registry', Revista Clinica Española (English Edition), 1 November, Vol. 220, No. 8, pp.480-494.

Chakraborty, I. and Maity, P. (2020) 'COVID-19 outbreak: migration, effects on society, global environment and prevention', Science of the Total Environment, 1 August, Vol. 728, p.138882.

Choinière, M., Ware, M.A., Pagé, M.G., Lacasse, A., Lanctôt, H., Beaudet, N., Boulanger, A., Bourgault, P., Cloutier, C., Coupal, L., De Koninck, Y., Dion, D., Dolbec, P., Germain, L., Martin, V., Sarret, P., Shir, Y., Taillefer, M.C., Tousignant, B., Trépanier, A. and Truchon, R. (2017) 'Development and implementation of a registry of patients attending multidisciplinary pain treatment clinics: the Quebec pain registry', Pain Research and Management, p.8123812.

Cornejo-Pareja, I.M., Gómez-Pérez, A.M., Fernández-García, J.C., Barahona San Millan, R., Aguilera Luque, A., de Hollanda, A., Jiménez, A., Jimenez-Murcia, S., Munguia, L. and Ortega, E. (2020) 'Coronavirus disease 2019 (COVID-19) and obesity. Impact of obesity and its main comorbidities in the evolution of the disease', European Eating Disorders Review, November, Vol. 28, No. 6, pp.799-815.

Dandachi, D., Geiger, G., Montgomery, M.W., Karmen-Tuohy, S., Golzy, M., Antar, A.A., Llibre, J.M., Camazine, M., Santiago, D-D. and Carlucci, P.M. (2020) 'Characteristics, comorbidities, and outcomes in a multicenter registry of patients with HIV and coronavirus disease-19', Clinical Infectious Diseases.

Hasan, S.M.S., Rivera, D., Wu, X., Christian, J.B. \& Tourassi, G. (2019) 'A knowledge graph approach for the secondary use of cancer registry data', 2019 IEEE EMBS International Conference on Biomedical \& Health Informatics (BHI), 19-22 May, pp.1-4.

Irie, H., Okamoto, H., Uchino, S., Endo, H., Uchida, M., Kawasaki, T., Kumasawa, J., Tagami, T., Shigemitsu, H., Hashiba, E., Aoki, Y., Kurosawa, H., Hatakeyama, J., Ichihara, N., Hashimoto, S. and Nishimura, M. (2020) 'The Japanese Intensive Care Patient Database (JIPAD): a national intensive care unit registry in Japan', Journal of Critical Care, 1 February, Vol. 55, pp.86-94.

Isaifan, R. (2020) 'The dramatic impact of coronavirus outbreak on air quality: has it saved as much as it has killed so far?', Global Journal of Environmental Science and Management, Vol. 6, pp.275-288.

Javanmard, S.H., Nasirian, M., Ataei, B., Vaseghi, G., Vaezi, A. and Changiz, T. (2020) 'Isfahan Covid-19 Registry (I-CORE): design and methodology', Journal of Research in Medical Sciences, March, Vol. 25, p.32.

Kazemi-Arpanahi, H., Moulaei, K. and Shanbehzadeh, M. (2020) 'Design and development of a web-based registry for Coronavirus (COVID-19) disease', Medical Journal of the Islamic Republic of Iran (MJIRI), 25 June, Vol. 34, No. 68, pp.482-490. 
Kazemi-Arpanahi, H., Vasheghani-Farahani, A., Baradaran, A., Ghazisaeedi, M., Mohammadzadeh, N. and Bostan, H. (2019) 'Development of a minimum data set for cardiac electrophysiology study ablation', Journal of Education and Health Promotion, May, Vol. 8, p.101.

Kodra, Y., de la PAZ, M. P., Coi, A., Santoro, M., Bianchi, F., Ahmed, F., Rubinstein, Y.R., Weinbach, J. and Taruscio, D. (2017) 'Data quality in rare diseases registries', Rare Diseases Epidemiology: Update and Overview, Springer, Vol. 1031, pp.149-164.

Mani, N.S., Budak, J.Z., Lan, K.F., Bryson-Cahn, C., Zelikoff, A., Barker, G.E., Grant, C.W., Hart, K., Barbee, C.J. and Sandoval, M.D. (2020) 'Prevalence of COVID-19 infection and outcomes among symptomatic healthcare workers in Seattle, Washington', Clinical Infectious Diseases, 15 November, Vol. 71,No. 10, pp.2702-2707.

Mills, E.H.A., Møller, A.L., Gnesin, F., Zylyftari, N., Broccia, M., Jensen, B., Schou, M., Fosbøl, E.L., Køber, L., Andersen, M.P., Phelps, M., Gerds, T. and Torp-Pedersen, C. (2020) 'National all-cause mortality during the COVID-19 pandemic: a Danish registry-based study', European Journal of Epidemiology, November, Vol. 35, No. 11, pp.1007-1019.

Mohammadzadeh, N., Gholamzadeh, M., Saeedi, S. and Rezayi, S. (2020a) 'The application of wearable smart sensors for monitoring the vital signs of patients in epidemics: a systematic literature review', Journal of Ambient Intelligence and Humanized Computing, 13 November, pp.1-5.

Mohammadzadeh, Z., Keikha, L. and Maserat, E. (2020b) 'Toward controlling coronavirus disease 2019 (COVID-19) pandemic by integrated registry systems', Health Scope, 31 August, Vol. 9, No. 3.

Sabbaghi, H., Daftarian, N., Suri, F., Mirrahimi, M., Madani, S., Sheikhtaheri, A., Khorrami, F., Saviz, P., Nejad, M.Z. and Tivay, A. (2020) 'The first inherited retinal disease registry in Iran: research protocol and results of a pilot study', Archives of Iranian Medicine, Vol. 23, No. 7, pp.445-454.

Shanbehzadeh, M., Kazemi-Arpanahi, H., Mazhab-Jafari, K. and Haghiri, H. (2020) 'Coronavirus disease 2019 (COVID-19) surveillance system: Development of COVID-19 minimum data set and interoperable reporting framework', Journal of Education and Health Promotion, 31 August, Vol. 9, p.203.

Tanne, J.H., Hayasaki, E., Zastrow, M., Pulla, P., Smith, P. and Rada, A.G. (2020) 'Covid-19: how doctors and healthcare systems are tackling coronavirus worldwide’, BMJ, 18 March, Vol. 368.

Uğur, N.G. and Akbıyık, A. (2020) 'Impacts of COVID-19 on global tourism industry: a cross-regional comparison', Tourism Management Perspectives, 1 October, Vol. 36, p.100744.

Uribarri, A., Núñez-Gil, I.J., Aparisi, A., Becerra-Muñoz, V.M., Feltes, G., Trabattoni, D., Fernández-Rozas, I., Viana-Llamas, M.C., Pepe, M., Cerrato, E., Capel-Astrua, T., Romero, R., Castro-Mejía, A.F., El-Battrawy, I., López-País, J., d'Ascenzo, F., Fabregat-Andres, O., Bardají, A., Raposeiras-Roubin, S., Marín, F., Fernández-Ortiz, A., Macaya, C., Estrada, V. and Investigators, H.C. (2020) 'Impact of renal function on admission in COVID-19 patients: an analysis of the international HOPE COVID-19 (Health Outcome Predictive Evaluation for COVID 19) Registry', Journal of Nephrology, August, Vol. 33, No. 4, pp.737-745.

Yang, M-J., Seegert, N., Gaulin, M., Looney, A., Orleans, B., Pavia, A., Stratford, K., Samore, M. and Alder, S. (2020) What is the Active Prevalence of COVID-19?, SSRN 3734463. 